\title{
PCH Regimen
}

National Cancer Institute

\section{Source}

National Cancer Institute. PCH Regimen. NCI Thesaurus. Code C63436.

A sequential regimen consisting of carboplatin and paclitaxel, followed by trastuzumab, used in the adjuvant setting for the treatment of HER-2/neu-positive breast cancer. 